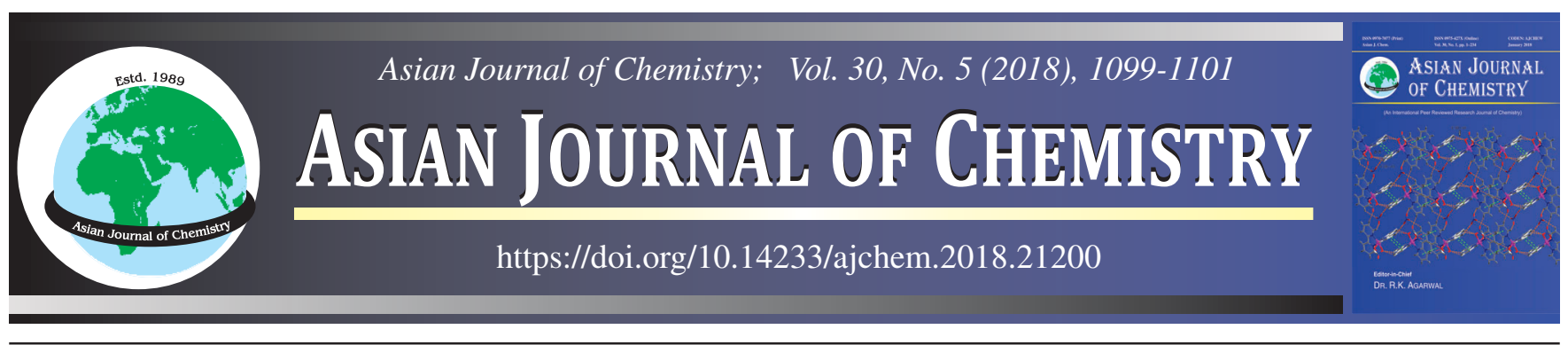

\title{
Guar Gum Stabilized Copper Oxide Nanoparticles with Enhanced Thermal and Antimicrobial Properties
}

\author{
B. Gajalakshmi ${ }^{1}$, S. Induja ${ }^{1, *}$, N. Sivakumar ${ }^{2}$ and P.S. Raghavan ${ }^{1}$
}

${ }^{1}$ Department of Chemistry, Hindustan Institute of Technology and Science, Chennai-603 103, India

${ }^{2}$ Centre for Clean Energy and Nano Convergence, Hindustan Institute of Technology and Science, Chennai-603 103, India

*Corresponding author: Fax: +91 44 27474208; Tel: +91 44 27474262; E-mail: sinduja@ hindustanuniv.ac.in

| The present investigation reports the synthesis and characterization of copper oxide nanofluids by one step chemical method using guar gum, a natural polymer as stabilizer. The samples were characterized using UV-visible spectroscopy and transmission emission microscopy. The thermo-physical properties such as thermal conductivity, viscosity were measured and antimicrobial activity was evaluated. The copper oxide nanofluids prepared under optimized conditions showed substantial increase in thermal conductivity (49.2\%) compared to the base fluids with relatively better stability and antimicrobial activity nearly equivalent to that of streptomycin (control sample).

Keywords: CuO Nanofluids, Thermal conductivity, Guar gum support, Antimicrobial activity.

\section{INTRODUCTION}

Nanofluids find potential applications in the different field of science and engineering. The conventional base fluids such as water, ethylene glycol, etc., exhibits low thermal conductivity [1]. In order to enhance the thermal conductivity, nano particles of metal/metal oxides, ceramic compounds, carbon nanotubes are dispersed in the base fluids [2-4]. Eventhough, various research groups have reported enhancement of thermal conductivity by addition of nanoparticles in base fluids, yet their stability remains a challenge [5]. The high surface area to volume ratio and the high surface energy of the nanoparticle is responsible for its poor stability. In order to avoid agglomeration of the metal/metal oxide nanoparticles, synthetic or natural polymers are being used in dispersion media as stabilizers. Nano-particles synthesized using natural polymers as capping/stabilizing agent have received great attention due to its low cost and high abundance. The present investigation reveals the in situ method of synthesizing copper oxide nanofluids stabilized using guar gum, the natural polymer, resulting in enhanced thermal conductivity and antibacterial property. The influence of synthesis parameters such as concentration of guar gum, amount of copper precursor and hydrazine hydrate on the stability of samples were studied and optimized.

\section{EXPERIMENTAL}

The preparation procedure involved dissolving calculated quantity of guar gum (S.D. Fine Chemicals) in distilled water under continuous vigorous stirring, followed by dropwise addition of cetyl trimethylammonium bromide (SRL Chemicals, dissolved in water). Calculated quantity of cupric acetate monohydrate (S.D. Fine Chemicals) dissolved in water was added to the above mixture followed by dropwise addition of diethanol amine (S.D. Fine Chemicals) till $\mathrm{pH}$ reaches around 7.5. The mixture was warmed to around $70^{\circ} \mathrm{C}$ and a dilute solution of hydrazine hydrate ( $80 \%$, S.D. Fine Chemicals) was added dropwise and stirring continued for $2 \mathrm{~h}$. Finally, the fluid was cooled to room temperature.

The nanofluid samples were characterized for UV-visible absorption behaviour using Shimadzu double beam monochromator spectrometer (UV-2540) equipped with an integrated sphere assembly ISR-240A in the range of 190-900 nm. The size of the copper oxide particles were analyzed using Transmission Emission Microscopy using JEOL 2100 at $200 \mathrm{kV}$ acceleration voltages. Transmission emission microscopy of the samples were made by dipping a carbon coated copper grid in a dilute suspension of nanofluid and dried. Thermal conductivity of nanofluids were measured using transient hot wire (THW, KD2-Pro-Decagon device) [6]. The in vitro antibacterial activity of copper oxide nanofluids were determined by well-diffusion method [7]. Staphylococcus aureus (gram positive) and Klebsiella pneumonia (gram negative) bacteria were selected for the antimicrobial study and analyzed in Jayagen Biologics Analytical Laboratory, Chennai, India. About $25 \mathrm{~mL}$ of molten Mueller Hinton agar was poured into a sterile petri plate (Himedia, Mumbai, India). The plates were allowed to solidify, after 
which $100 \mu \mathrm{L}$ of $18 \mathrm{~h}$ grown (optical density adjusted to 0.6 ) above said pathogenic bacteria and fungal cultures were transferred onto plate and spread using sterile L-rod. After $5 \mathrm{~min}$ setting of pathogenic microbes, a sterile cork-bore was used to make $5 \mathrm{~mm}$ well on the agar. The test samples were dissolved in sterile saline and loaded in to wells with various concentrations such as $25 \mathrm{~L} /$ well, $50 \mathrm{~L} /$ well, $75 \mathrm{~L} /$ well and $100 \mathrm{~g} /$ well. The streptomycin amended $(20 \mu \mathrm{L})$ well served as positive control.

\section{RESULTS AND DISCUSSION}

Synthetic parameters viz., weight of copper acetate, volume $\%$ of surfactant, volume of hydrazine hydrate, quantity of guar gum, etc., were studied. The influence of copper acetate on the stability was studied by varying the amount of the same between $0.05-0.3 \%$ by weight. It was found that weight percent of copper acetate did not influence the stability of nanofluids, within the selected range. The influence of guar gum content on the stability of nanofluids was studied by varying the composition between $0.01-0.2 \%$ by weight. It was observed that with the increase in quantity of guar gum, up to $0.05 \%$ the stability increased but any further increase beyond $0.05 \%$ decreases the stability of nanofluids. Hence, guar gum content of $0.05 \%$ was found to form stable nanofluid. The volume percent of hydrazine hydrate added during the preparation of nanofluid was optimized as $2.5 \%$, below which partial oxidation of copper species was observed and beyond which resulted in agglomeration of particles. The UV-visible spectra showed absorption bands for copper(I) oxide at around $500 \mathrm{~nm}$ as observed by earlier researchers [8] and for $\mathrm{CuO}$, it has been reported between 270$300 \mathrm{~nm}$ [9]. The present sample showed an absorption band at around $270 \mathrm{~nm}$ which confirms the presence of copper oxide in +2 oxidation state (Fig. 1).

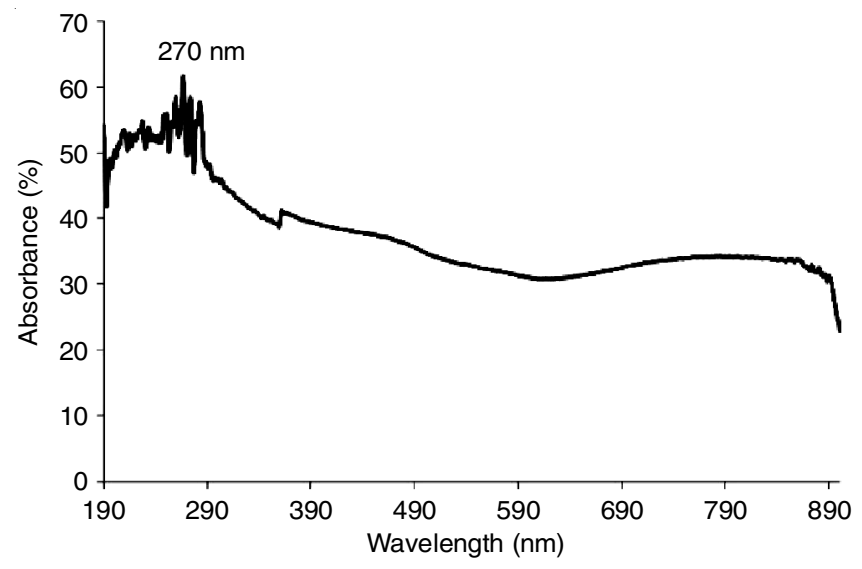

Fig. 1. UV-visible absorption of copper oxide nanofluids

The transient hot wire method was used for measuring the thermal conductivity of nanofluids with different concentration of copper oxide nanoparticles $(0.05,0.1,0.2$ and $0.3 \mathrm{wt} \%)$. In this method, the rate of rise in temperature of micro-wire for an applied voltage with time was used to determine the thermal conductivity of fluid. Heat flux generated in the micro-wire due to the supply of voltage was transferred to the static fluid around it. The higher the thermal conductivity of the fluid, the lower will be the temperature rise of wire. The change in temperature with time was obtained from the change in resistance, which in turn was obtained from the change in voltage. The copper oxide nanofluids exhibited higher thermal conductivity values compared to the base liquid (distilled water) (Table-1). The average particle size as estimated from TEM was found to be between 20-40 nm (Fig. 2).

\begin{tabular}{|c|c|c|c|c|c|}
\hline \multirow[b]{3}{*}{$\begin{array}{c}\text { Temp. } \\
\left({ }^{\circ} \mathrm{C}\right)\end{array}$} & \multicolumn{5}{|c|}{$\begin{array}{l}\text { TABLE-1 } \\
\text { THERMAL CONDUCTIVITY OF COPPER OXIDE } \\
\text { NANOFLUIDS AT DIFFERENT TEMPERATURES }\end{array}$} \\
\hline & \multicolumn{5}{|c|}{ Thermal conductivity (W/mK) of nanofluids } \\
\hline & $\begin{array}{c}0 \% \\
\mathrm{CuO} \\
\text { (water) }\end{array}$ & $\begin{array}{c}0.05 \% \\
\mathrm{CuO}\end{array}$ & $\begin{array}{c}0.10 \% \\
\mathrm{CuO}\end{array}$ & $\begin{array}{c}0.20 \% \\
\mathrm{CuO}\end{array}$ & $\begin{array}{c}0.30 \% \\
\mathrm{CuO}\end{array}$ \\
\hline 30 & 0.582 & 0.621 & 0.835 & 1.06 & 1.22 \\
\hline 40 & 0.591 & 0.683 & 0.890 & 1.19 & 1.39 \\
\hline 50 & 0.612 & 0.762 & 0.926 & 1.29 & 1.42 \\
\hline 60 & 0.630 & 0.856 & 0.950 & 1.39 & 1.61 \\
\hline 70 & 0.642 & 0.917 & 1.120 & 1.42 & 1.68 \\
\hline 80 & 0.670 & 1.111 & 1.220 & 1.49 & 1.72 \\
\hline 90 & 0.690 & 1.384 & 1.320 & 1.52 & 1.79 \\
\hline
\end{tabular}

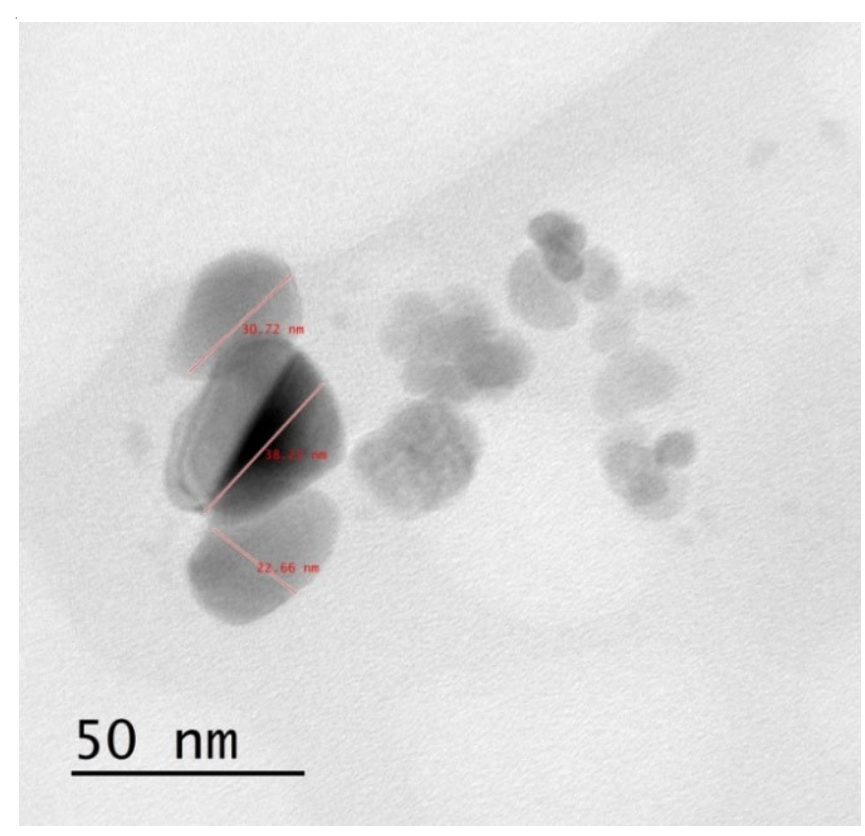

Fig. 2. TEM image of copper oxide nanofluids

As expected, thermal conductivity increases with the increase in concentration of copper oxide and as well as temperature (Fig. 3). The maximum value of $1.79 \mathrm{~W} / \mathrm{mK}$ was observed for nanofluids containing $0.3 \mathrm{wt} \%$ of copper oxide at $90^{\circ} \mathrm{C}$. From literature wet chemical method of preparation of $\mathrm{CuO}$ nanofluids with $10 \mathrm{~nm}$ particle size showed $1.3 \mathrm{~W} / \mathrm{mK}$ [10]. Instead of transient hot-wire method, shell-coil method was used for analyzing $\mathrm{CuO}$ nanofluids by Srinivas and Vinod [11]. Twostep method of synthesizing $\mathrm{CuO}$ nanofluids by Liu et al. [12] showed $22 \%$ increase in thermal conductivity with 5 vol. \% of $\mathrm{CuO}$. With $0.2 \%$ volume fraction of $\mathrm{CuO}$ nanofluid, $30 \%$ increase in thermal conductivity was observed [13]. By single step method, $20 \mathrm{~nm} \mathrm{CuO}$ nanofluid was prepared which showed $12.4 \%$ increase in thermal conductivity [14]. Poly(vinyl pyrrolidone) was used as stabilizing agent for $\mathrm{CuO}$ nanofluid by Sahooli et al. [15], which showed $31 \%$ increase in thermal conductivity. In the present study, nanofluids with 0.3 vol. $\%$ 


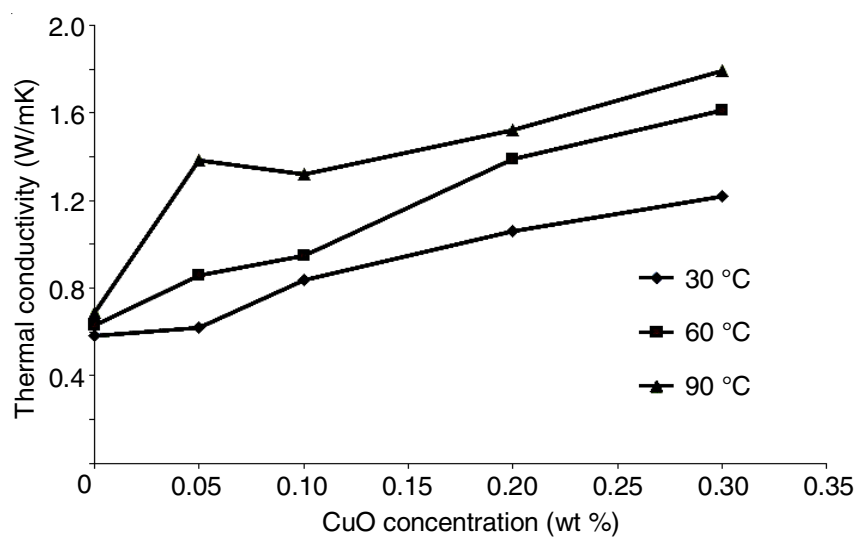

Fig. 3. Thermal conductivity of nanofluids with varying copper oxide content at different temperatures

of $\mathrm{CuO}$ showed nearly $49 \%$ increase in thermal conductivity compared to base fluid.

The thermo-physical properties of the samples (thermal conductivity and viscosity) at different temperatures were recorded in order to evaluate the efficiency copper oxide nanofluids for heat transfer applications. The viscosity of nanofluids with different concentration of copper oxide were studied in temperature ranging from 30 to $90^{\circ} \mathrm{C}$, and the results were presented in Table-2. The viscosity of nanofluids was found to decrease with increase in temperature and increase with increase in concentration of $\mathrm{CuO}$.

\begin{tabular}{|c|c|c|c|c|c|}
\hline \multicolumn{6}{|c|}{$\begin{array}{l}\text { TABLE-2 } \\
\text { INFLUENCE OF TEMPERATURE AND COPPER OXIDE } \\
\text { CONCENTRATION ON VISCOSITY OF NANOFLUIDS }\end{array}$} \\
\hline \multirow{2}{*}{$\begin{array}{c}\text { Temp. } \\
\left({ }^{\circ} \mathrm{C}\right)\end{array}$} & \multicolumn{5}{|c|}{ Viscosity of nanofluids $\left(\mathrm{N} \mathrm{s} / \mathrm{m}^{2}\right) \times 10^{-3}$} \\
\hline & $\begin{array}{l}\text { Distilled } \\
\text { water }\end{array}$ & $\begin{array}{c}0.05 \% \\
\mathrm{CuO}\end{array}$ & $\begin{array}{c}0.10 \% \\
\mathrm{CuO}\end{array}$ & $\begin{array}{c}0.20 \% \\
\mathrm{CuO}\end{array}$ & $\begin{array}{c}0.30 \% \\
\mathrm{CuO}\end{array}$ \\
\hline 30 & 0.95 & 1.62 & 1.99 & 2.33 & 2.56 \\
\hline 50 & 0.82 & 1.22 & 1.91 & 2.00 & 2.35 \\
\hline 70 & 0.77 & 1.16 & 1.79 & 1.82 & 1.92 \\
\hline 90 & 0.71 & 0.94 & 1.53 & 1.66 & 1.77 \\
\hline
\end{tabular}

Copper oxide nanoparticles suspended in guar gum exhibited bactericidal effect almost equivalent to streptomycin for both gram positive and gram negative bacteria. The antibacterial activity against Staphylococcus aureus and Klebsiella pneumonia is shown in Table-3. The results showed that the activity was equivalent to that of control (streptomycin).

\begin{tabular}{lccccc}
\multicolumn{7}{c}{ TABLE-3 } \\
COPPER OXIDE NANOPARTICLES AGAINST \\
GRAM-POSITIVE AND GRAM-NEGATIVE BACTERIA \\
\hline \multirow{2}{*}{$\begin{array}{c}\text { Name of the } \\
\text { organism }\end{array}$} & 12.5 & 25.0 & 37.5 & 50.0 & Streptomycin \\
& $\mu \mathrm{g}$ & $\mu \mathrm{g}$ & $\mu \mathrm{g}$ & $\mu \mathrm{g}$ & $20 \mu \mathrm{g}$ \\
\hline S. aureus & 28 & 30 & 30 & 30 & 35 \\
K. pneumoniae & 18 & 20 & 22 & 22 & 30 \\
\hline
\end{tabular}

\section{Conclusion}

Aqueous copper oxide nanofluids were prepared in situ by suspending the nanoparticles in guar gum matrix. The stability of nanofluids were enhanced by using cetyltrimethylammonium bromide. The copper oxide nanofluids exhibited good thermal conductivity at room temperature and increased significantly with temperature (around $49 \%$ ). The antibacterial activity was found to be equivalent to that of control sample (streptomycin) against both gram positive and gram negative bacteria.

\section{REFERENCES}

1. P. Selvakumar and S. Suresh, J. Nanosci. Nanotechnol., 14, 2325 (2014); https://doi.org/10.1166/jnn.2014.8470.

2. W. Chen, C. Zou, X. Li and L. Li, Int. J. Heat Mass Transfer, 107, 264 (2017);

https://doi.org/10.1016/j.ijheatmasstransfer.2016.11.048.

3. M.A. Serebryakova, A.V. Zaikovskii, S.Z. Sakhapov, D.V. Smovzh, G.I. Sukhinin and S.A. Novopashin, Int. J. Heat Mass Transfer, 108, 1314 (2017);

https://doi.org/10.1016/j.ijheatmasstransfer.2016.12.098.

4. H.S. Moghaieb, H.M. Abdel-Hamid, M.H. Shedid and A.B. Helali, Appl. Therm. Eng., 115, 152 (2017); https://doi.org/10.1016/j.applthermaleng.2016.12.099.

5. C. Anushree and J. Philip, J. Mol. Liq., 222, 350 (2016); https://doi.org/10.1016/j.molliq.2016.07.051.

6. E. Cohen and L. Glicksman, J. Heat Transfer, 136, 041301 (2014); https://doi.org/10.1115/1.4025921.

7. H. Jahangirian, M.J. Haron, H.S.I. Mohd, R. Rafiee-Moghaddam, L. Afsah-Hejri, V. Abdollahi, M. Rezayi and N. Vafaei, Dig. J. Nanomater. Biostruct., 8, 1263 (2013).

8. T. Jiang, T. Xie, Y. Zhang, L. Chen, L. Peng, H. Li and D. Wang, Phys. Chem. Chem. Phys., 12, 15476 (2010);

https://doi.org/10.1039/c0cp01228a.

9. K.V. Ragavan and N.K. Rastogi, Sens. Actuators B, 229, 570 (2016); https://doi.org/10.1016/j.snb.2016.02.017.

10. H. Zhu, D. Han, Z. Meng, D. Wu and C. Zhang, Nanoscale Res. Lett., 6, 181 (2011); https://doi.org/10.1186/1556-276X-6-181.

11. T. Srinivas and A.V. Vinod, Procedia Eng., 127, 1271 (2015); https://doi.org/10.1016/j.proeng.2015.11.483.

12. M.-S. Liu, M.C.-C. Lin, I.-T. Huang and C.-C. Wang, Chem. Eng. Technol., 29, 72 (2006); https://doi.org/10.1002/ceat.200500184.

13. P. Selvakumar and S. Suresh, Exp. Therm. Fluid Sci., 40, 57 (2012); https://doi.org/10.1016/j.expthermflusci.2012.01.033.

14. R. Manimaran, K. Palaniradja, N. Alagumurthi, S. Sendhilnathan and J. Hussain, App. Nanosci., 4, 163 (2014); https://doi.org/10.1007/s13204-012-0184-7.

15. M. Sahooli, S. Sabbaghi and M.S. Niassar, Int. J. Nanosci. Nanotechnol., 8, 27 (2012) 